\title{
Serum drug levels to diagnose non-adherence in acute decompensated heart failure
}

\author{
Miroslav Solar ${ }^{\mathrm{a}, \mathrm{b}}$, Radek Pelouch ${ }^{\mathrm{a}, \mathrm{b}}$, Viktor Vorisek, Vera Furmanova ${ }^{\mathrm{c}}$, Jiri Cerala ${ }^{\mathrm{a}, \mathrm{b}}$
}

Background. The aim of this study was to analyze medication non-adherence by measuring serum drug levels (SDL) in patients presenting with acute decompensated heart failure (ADHF).

Methods. Included in the study were chronic heart failure patients presenting with signs of acute decompensation. Blood sampling for the measurement of SDL was performed shortly after presentation. SDL were measured using liquid chromatography coupled with mass spectrometry. The estimation of SDL was calculated from the recommended chronic cardiac medications with the exception of drugs administered as part of the acute treatment prior to blood sampling. The patients were labeled as non-adherent when any one of the evaluated medications was not found in the serum.

Results. Fifty patients with ADHF were prospectively enrolled. All of the evaluated drugs were detected in the sera of $28(56 \%)$ patients. Non-adherence was diagnosed in the remaining $22(44 \%)$ patients. None of the evaluated medications was detected in the sera of $5(10 \%)$ patients.

Conclusion. The estimation of SDL indicates that non-adherence to the recommended chronic therapy is a common problem among patients presenting with ADHF. This method should be an essential aspect of routine clinical evaluation in these patients.

Key words: acute heart failure, drug non-adherence, pharmacotherapy, serum drug levels

Received: April 29, 2016; Accepted: May 27, 2016; Available online: June 3, 2016

http://dx.doi.org/10.5507/bp.2016.031

${ }^{a}$ Department of Internal Medicine, Faculty of Medicine in Hradec Kralove, Charles University in Prague, Hradec Kralove, Czech Republic ${ }^{b} 7^{\text {st }}$ Department of Internal Medicine - Cardioangiology, University Hospital Hradec Kralove, Czech Republic

cInstitute of Clinical Biochemistry and Diagnostics, University Hospital Hradec Kralove, Czech Republic Corresponding author: Miroslav Solar, e-mail:miroslav.solar@fnhk.cz.

\section{INTRODUCTION}

Acute decompensated heart failure (ADHF) is a common reason for emergency room visits and unplanned hospitalizations. One of the factors contributing to acute decompensation is non-adherence to recommended medication $^{1,2}$. The diagnosis of non-adherence is clinically important in order to plan proper management of heart failure patients. However, the diagnosis of non-adherence is challenging in the real life clinical setting.

The adherence to prescribed medication can be evaluated by pill counts, rates of prescription refills and electronic medication monitors ${ }^{3}$. Monitoring techniques have high specificity in the detection of non-adherence; however. Sensitivity is reduced because no technique is able to document if the prescribed drugs were actually ingested $^{4}$. The measurement of serum or urinary drug levels is a novel approach for adherence assessment that provides reliable information on whether the recommended medications were taken ${ }^{5-9}$, and we used this approach to analyze the prevalence of medication non-adherence in patients presenting with ADHF.

\section{METHODS}

The study was approved by the Local Ethics committee, and the participants gave written informed consent. Chronic heart failure patients presenting with signs of acute decompensation were enrolled. The diagnosis of ADHF was made based on the progression of heart failure symptoms and signs of fluid retention and/or pulmonary congestion. Blood sampling for the measurement of serum drug levels (SDL) was performed shortly after presentation at the emergency department or hospital admission.

\section{The determination of serum drug levels}

The determination of serum drug levels was performed by liquid chromatography coupled with mass spectrometry (LC-MS) (ref. ${ }^{10,11}$ ). Prior to the chromatographic separation, the serum samples were prepared by liquid-liquid extraction using a mixture of ethyl acetate and dichloromethane. The chromatographic separation was performed on a reversed-phase column with gradient flow of the mobile phase $(0.05 \mathrm{M}$ formic acid and acetonitrile). The detection of the analyzed substances was performed on a linear ion-trap mass spectrometer (LTQ XL, Thermo Scientific) using electrospray ionization. The parameters of the mass spectrometer were adjusted for each individual analyte (analyzed drug). Pooled blank sera from healthy volunteers were used for method opti- 
mization and validation. Blank serum samples enriched with defined amounts of determined substances were used for calibration of the analytic method.

Using this precise and sensitive technique, we were able to measure the serum concentrations of betablockers, angiotensin receptor blockers, calcium channel blockers and diuretics, including spironolactone. In each patient in whom SDL were evaluated, the LC-MS analysis was focused primarily on the prescribed chronic cardiac medications with the exception of drugs administered as acute treatment prior to obtaining the blood samples; the serum concentrations of other medications were not systematically evaluated.

\section{Interpretation of the results}

Because clinical interpretation of serum drug concentrations is difficult, any quantifiable amount of the evaluated drug was interpreted to mean that the drug was taken. By applying this criterion for non-adherence, we eliminated uncertainties and ethical bias from the interpretation of low concentrations of the evaluated medications in the serum.

The patients were labeled as non-adherent when any of the evaluated medication, with the exception of furosemide, was not found in the serum. The adherence assessment for furosemide reflected the short plasma half-life of this drug; if furosemide was not detectable in the serum and there was a delay greater than 6 hours between the presumed drug ingestion time and blood sampling time, the respective result was considered inconclusive and excluded from the final analysis.

Because the results of the adherence assessment were not readily available, the results did not impact the immediate clinical management of the patients enrolled; however, the results were accessible during the follow-up visits.

All of the statistical calculations were performed using the MedCalc ${ }^{\circledR}$ software, version 11.6 (Mariakerke, Belgium).

\section{RESULTS}

Fifty patients with ADHF were prospectively enrolled. Seven patients were treated on an outpatient basis, and 43 were hospitalized. One patient died during hospitalization. The principal characteristics of the patients are summarized in Table 1.

Based on clinical evaluations prior to SDL results availability, the episode of decompensation was attributed to acute myocardial ischemia in 5 patients, acute infection in 5, tachyarrhythmia in 2, uncontrolled arterial hypertension in 1, progressive valvular disorder in 1, and anemia in 1 . In 1 patient, acute heart failure was caused by an inappropriate medication switch, and 3 patients overtly admitted medication non-adherence. The precipitating cause of acute decompensation remained unclear in 31 (62\%) patients.

All of the evaluated drugs were detected in the sera of $28(56 \%)$ patients. Non-adherence was diagnosed in the remaining 22 (44\%) patients. There was no other ex-
Table 1. Principle characteristics of the study patients.

\begin{tabular}{lc}
\hline N. of patients (women) & $50(22)$ \\
Age (years) & $70(45-83)$ \\
Left ventricular ejection fraction (\%) & $30(10-75)$ \\
GFR $<50 \mathrm{~mL} / \mathrm{min}\left(\mathrm{n}\right.$. of patients) ${ }^{\mathrm{a}}$ & $23(46 \%)$ \\
NT-pro BNP $(\mathrm{pg} / \mathrm{mL})^{\text {a }}$ & $2651(449-34995)$ \\
Etiology of chronic heart failure & \\
$\quad$ Coronary artery disease & $14(28 \%)$ \\
Coronary artery disease & $14(28 \%)$ \\
and significant valvular disease & \\
Cardiomyopathy & $8(16 \%)$ \\
Significant valvular disease & $6(12 \%)$ \\
Cor pulmonale & $3(6 \%)$ \\
Arterial hypertension & $2(4 \%)$ \\
Multifactorial/unknown & $3(6 \%)$ \\
\hline
\end{tabular}

The table describes the principal characteristics of the study patients. If not stated otherwise, the data are expressed as medians (ranges). N., denotes the number. GFR, denotes glomerular filtration rate estimated by MDRD formula, ${ }^{\text {a }}$ denotes data obtained at initial evaluation.

Table 2. Adherence assessment.

\begin{tabular}{lc}
\hline Evaluation of serum drug levels & \\
N. of drugs prescribed for heart disease & $4(3-6)$ \\
N. of drugs analyzed & $2(1-4)$ \\
N. of completely adherent patients & $28(56 \%)$ \\
N. of partially non-adherent patients & $17(34 \%)$ \\
N. of completely non-adherent patients & $5(10 \%)$ \\
\hline Non-adherence to individual drugs/drug classes \\
\multicolumn{2}{l}{ Angiotensin receptor blockers } \\
Betablockers & $25 \%(2 / 8)$ \\
Furosemide & $28 \%(13 / 47)$ \\
Thiazides & $21 \%(3 / 14)$ \\
Spironolactone & $16 \%(2 / 12)$ \\
Calcium channel blockers & $18 \%(2 / 11)$ \\
\hline
\end{tabular}

The table describes the main study results. Unless stated otherwise, the data are expressed as medians (ranges). N., denotes the number. a non-adherence to individual drugs/drug classes was calculated as a percentage of patients where the analyzed drug was not detectable compared to the number of patients where the analyzed medication was evaluated. The respective numbers are in the brackets.

planation for the decompensation in 13 of the 22 nonadherent patients. The detailed SDL results are described in Table 2.

\section{DISCUSSION}

The study was motivated by observations of patients with difficulties controlling arterial hypertension ${ }^{5-9}$. In these patients, the estimation of serum or urinary drug levels appears to be a valuable examination to enable the differentiation between true resistant hypertension and medication non-adherence.

Surprisingly, in ADHF patients enrolled in our study, the non-adherence rate was similar to that observed in patients presenting with difficult-to-treat hypertension ${ }^{5-9}$ 
despite the fact that heart failure, in contrast to arterial hypertension, causes troublesome and limiting symptoms.

To the best of our knowledge, the use of serum or urinary drug levels for the adherence assessment in heart failure patients has not been reported before. The previous studies assessing medication adherence in heart failure patients are based mainly on the self-reporting or the analysis of prescription refills ${ }^{12-18}$, and the frequency of non-adherence may have been underestimated.

Compared to other techniques, the estimation of serum drug levels allows reliable and easily accessible identification of actual non-adherence to the recommended medication; this information may be of high clinical value when searching for causes of acute cardiac decompensation in individual patients.

We can only speculate about the reasons for the frequent non-adherence among patients enrolled in this study. In our opinion, the non-adherence among ADHF patients resulted mainly from the underestimation of the importance of the chronic pharmacotherapy in the treatment of chronic heart failure. Drug related side effects leading to the interruption of recommended medications might also play a role. We have no reason to assume that socio-economic factors contributed to the observed nonadherence; the health care system in our country enables unlimited prescription for cardiac medications at negligible costs for those with very low incomes.

Confirmed non-adherence is a clinically relevant finding that indicates a need for a special attention. Instead of searching for new therapeutic options, non-adhering patients require focused counseling and close supervision. In our experience, extensive communication may help to establish good relationships with the patient and to manage the problem successfully.

The study has the following limitations:

First, we were not able to reliably assess the adherence to angiotensin-converting enzyme inhibitors due to analytical limitations.

Second, in a significant number of patients, furosemide was excluded from the adherence assessment because either it was administered intravenously as an acute pre-hospital treatment or there was a long time delay between the presumed ingestion time and the blood sampling time for SDL measurement.

Third, it is important to note that the single assessment of SDL provides information about actual adherence only. Therefore, it is possible that among the patients, who were labeled as adherent in our study, some patients started to take the recommended medical therapy shortly before presentation when heart failure symptoms deteriorated.

These limitations may have led to an underestimation of the real occurrence of non-adherence.

Although the number of patients in our study was small, we do not believe that increasing the number of patients would principally change the study results given the considerable non-adherence rate.

\section{CONCLUSION}

The estimation of serum drug levels indicates that non-adherence to the recommended chronic therapy is a common problem among patients presenting with acute decompensated heart failure. We believe that this test should become a component of complex clinical assessment of acute heart failure patients.

\section{ABBREVIATIONS}

ADHF, Acute decompensated heart failure; SDL, Serum drug levels.

Acknowledgement: This work was supported by the research project PRVOUK 037/03.

Author contributions: MS: study design, collection and analysis of the clinical data, writing manuscript; RP: study design, collection and analysis of the clinical data; VV, $\mathrm{VF}$ : the measurement of serum drug levels and analysis of the laboratory data, manuscript review; JC: study design, collection and analysis of the clinical data, writing of the manuscript.

Conflict of interest statement: None declared.

\section{REFERENCES}

1. Yancy CW, Jessup M, Bozkurt B, Butler J, Casey DE Jr, Drazner MH, Fonarow GC, Geraci SA, Horwich T, Januzzi JL, Johnson MR, Kasper EK, Levy WC, Masoudi FA, Mcbride PE, Mcmurray JJ, Mitchell JE, Peterson PN, Riegel B, Sam F, Stevenson LW, Tang WH, Tsai EJ, Wilkoff BL. ACCF/AHA Guideline For The Management Of Heart Failure: A Report Of The American College Of Cardiology Foundation/ American Heart Association Task Force On Practice Guidelines. J Am Coll Cardiol 2013;62(16)E147-239.

2. Mcmurray JJ, Adamopoulos S, Anker SD, Mcmurray JJ, Adamopoulos S, Anker SD, Auricchio A, Böhm M, Dickstein K, Falk V, Filippatos G, Fonseca C, Gomez-Sanchez MA, Jaarsma T, Køber L, Lip GY, Maggioni AP, Parkhomenko A, Pieske BM, Popescu BA, Rønnevik PK, Rutten FH, Schwitter J, Seferovic P, Stepinska J, Trindade PT, Voors AA, Zannad F, Zeiher A; Task Force For The Diagnosis And Treatment Of Acute Andchronic Heart Failure 2012 Of The European Society Of Cardiology, Bax JJ, Baumgartner H, Ceconi C, Dean V, Deaton C, Fagard R, Funck-Brentano C, Hasdai D, Hoes A, Kirchhof P, Knuuti J, Kolh P, Mcdonagh T, Moulin C, Popescu BA, Reiner Z, Sechtem U, Sirnes PA, Tendera M, Torbicki A, Vahanian A, Windecker S, Mcdonagh T, Sechtem U, Bonet LA, Avraamides P, Ben Lamin HA, Brignole M, Coca A, Cowburn P, Dargie H, Elliott P, Flachskampf FA, Guida GF, Hardman S, lung B, Merkely B, Mueller C, Nanas JN, Nielsen OW, Orn S, Parissis JT, Ponikowski P; ESC Committee For Practice Guidelines. ESC Guidelines For The Diagnosis And Treatment Of Acute And Chronic Heart Failure 2012: The Task Force For The Diagnosis And Treatment Of Acute And Chronic Heart Failure 2012 Of The European Society Of Cardiology. Developed In Collaboration With The Heart Failure Association (HFA) Of The ESC. Eur J Heart Fail 2012;14(8):80369.

3. Osterberg L, Blaschke T. Adherence To Medication. N Engl J Med 2005;353(5):487-97.

4. Van Onzenoort HA, Verberk WJ, Kessels AG, Kroon AA, Neef C, Van Der Kuy PH, De Leeuw PW. Assessing Medication Adherence Simultaneously By Electronic Monitoring And Pill Count In Patients With Mild-To-Moderate Hypertension. Am J Hypertens 2010;23(2):149-54.

5. Ceral J, Habrdova V, Vorisek V, Bima M, Pelouch R, Solar M. DifficultTo-Control Arterial Hypertension Or Uncooperative Patients? The 
Assessment Of Serum Antihypertensive Drug Levels To Differentiate Non-Responsiveness From Non-Adherence To Recommended Therapy. Hypertens Res 2001;34(1):87-90.

6. Strauch B, Petrak O, Zelinka T, Rosa J, Somloova Z, Indra T, Chytil L, Marešová V, Kurcová I, Holaj R, Wichterle D, Widimský J Jr. Precise Assessment Of Noncompliance With The Antihypertensive Therapy In Patients With Resistant Hypertension Using Toxicological Serum Analysis. J Hypertens 2013;31(12):2455-61.

7. Jung O, Gechter JL, Wunder C, Paulke A, Bartel C, Geiger H, Toennes SW. Resistant Hypertension? Assessment Of Adherence By Toxicological Urine Analysis. J Hypertens 2013;31(4):766-74.

8. Tomaszewski M, White C, Patel P, Masca N, Damani R, Hepworth J, Samani NJ, Gupta P, Madira W, Stanley A, Williams B. High Rates Of Non-Adherence To Antihypertensive Treatment Revealed By HighPerformance Liquid Chromatography-Tandem Mass Spectrometry (HP LC-MS/MS) Urine Analysis. Heart 2014;100(11):855-61.

9. Brinker S, Pandey A, Ayers C, Price A, Raheja P, Arbique D, Das SR, Halm EA, Kaplan NM, Vongpatanasin W. Therapeutic Drug Monitoring Facilitates Blood Pressure Control In Resistant Hypertension. J Am Coll Cardiol 2014;63(8):834-5.

10. Maurer HH. Multi-Analyte Procedures For Screening For And Quantification Of Drugs In Blood, Plasma, Or Serum By Liquid Chromatography-Single Stage Or Tandem Mass Spectrometry (LC MS Or LC-MS/MS) Relevant To Clinical And Forensic Toxicology. Clin Biochem 2005;38(4):310-8.

11. Kolocouri F, Dotsikas Y, Apostolou C, Kousoulos C, Loukas YL. Simultaneous Determination Of Losartan, EXP-3174 And Hydrochlorothiazide In Plasma Via Fully Automated 96-Well-Format-
Based Solid-Phase Extraction And Liquid Chromatography-Negative Electrospray Tandem Mass Spectrometry. Anal Bioanal Chemistry 2007;387(2):593-601.

12. Vinson JM, Rich MW, Sperry JC, Shah AS, Mcnamara T. Early Readmission Of Elderly Patients With Congestive Heart Failure. J Am Geriatr Soc 1990;38(12):1290-5.

13. Van Der Wal MH, Jaarsma T, Van Veldhuisen DJ. Non-Compliance In Patients With Heart Failure; How Can We Manage It? Eur J Heart Fail 2005;7(1):5-17.

14. Murray MD, Young J, Hoke S, Tu W, Weiner M, Morrow D, Stroupe KT, Wu J, Clark D, Smith F, Gradus-Pizlo I, Weinberger M, Brater DC. Pharmacist Intervention To Improve Medication Adherence In Heart Failure: A Randomized Trial. Ann Intern Med 2007;146(10): 714-25.

15. Van Der Wal MH, Jaarsma T. Adherence In Heart Failure In The Elderly: Problem And Possible Solutions. Int J Cardiol 2008;125(2):203-8.

16. Murray MD, Tu W, Wu J, Morrow D, Smith F, Brater DC. Factors Associated With Exacerbation Of Heart Failure Include Treatment Adherence And Health Literacy Skills. Clin Pharmacol Ther 2009;85(6):651-8.

17. Ambardekar AV, Fonarow GC, Hernandez AF, Pan W, Yancy CW, Krantz MJ; Get With The Guidelines Steering Committee And Hospitals. Characteristics And In-Hospital Outcomes For Nonadherent Patients With Heart Failure: Findings From Get With The Guidelines-Heart Failure (GWTG-HF), Am Heart J 2009;158(4):644-52.

18. Riegel B, Moelter ST, Ratcliffe SJ, Pressler SJ, De Geest S, Potashnik S, Fleck D, Sha D, Sayers SL, Weintraub WS, Weaver TE, Goldberg LR. Excessive daytime sleepiness is associated with poor medication adherence in adults with heart failure. J Card Fail 2011:17(4):340-8. 